\title{
Juventudes e movimento social: o processo de constituição do Levante Popular de Juventude no Ceará
}

Jaiane Araujo de Oliveira ${ }^{1}$

\begin{abstract}
Resumo:
O objetivo deste artigo é discutir o processo de constituição do Levante Popular de Juventude (LPJ) no estado do Ceará. O movimento está organizado em: frente estudantil, frente territorial e frente camponesa. A mais, os acampamentos nacionais e estaduais são instâncias de deliberação e organização do movimento. A principal ferramenta de organização são as células que funcionam em cada frente de atuação do movimento, seu objetivo é estabelecer um canal de diálogo entre os(as) jovens de seus territórios, de modo que possibilite ao LPJ conhecer melhor os(as) jovens, sua realidade, buscando uma maneira mais efetiva de incluir a juventude na luta social. Existe uma profunda relação no fazer e no construir o movimento com o jeito juvenil de ser, aliando a ludicidade, a irreverência, a criatividade, bem como o compromisso político em manter uma organização social da juventude. O LPJ se identifica como um movimento social de/com juventude, o qual reúne jovens de territórios distintos e que, no contexto de sua ação política, tem se colocado em cena, produzindo novas práticas e modos de fazer, os quais denominamos de atividades educativas.
\end{abstract}

\section{Palavras-chave:}

Movimentos Sociais. Levante Popular de Juventude. Juventudes.

\section{Youth and social movement: the process of constituting the popular youth uprising in Ceará}

\begin{abstract}
The objective of this article is to discuss the process of constituting the Popular Youth Uprising (LPJ) in the State of Ceará. The movement is organized in: student front, territorial front and peasant front. Furthermore, national and state camps are instances of deliberation and organization of the movement. The main organizing tool are the cells that work on each front of the movement, the objective is to establish a channel of dialogue between the young people of their territories, so that it allows the LPJ to know the young people better, their reality, seeking a more effective way to include youth in the social struggle. There is a deep relationship to make and to build the movement with the youthful
\end{abstract}

\footnotetext{
1 Doutora em Educação, Professora do Instituto Federal de Ciência e Tecnologia do Estado do Ceará. E-mail: oliveira.jaiane@ifce.edu.br. ORCID iD: https://orcid.org/0000-0001-7131-7310.

2 Doutora em Sociologia, Professora da Universidade Federal do Ceará. E-mail: celecinavs@gmail.com. ORCID iD: https://orcid.org/ 0000-0001-7662-0255.
} 
way of being, combining playfulness, irreverence, creativity, as well as the political commitment to maintain a social organization of youth. The LPJ identifies itself as a social movement of/with youth, which brings together young people from different territories and that, in the context of its political action, has been taking the stage producing new practices and ways of doing, which we call educational activities.

Keywords: Social Movements. Popular Youth Uprising. Youth.

\section{Juventudes y movimiento social: el proceso de constitución del levantamiento popular juvenil en el Ceará}

Resumen: El objetivo de este artículo es discutir el proceso de constitución de Levantamiento Popular de la Juventud (LPJ) en el Estado de Ceará. El movimiento se organiza en: frente estudiantil, frente territorial y frente campesino. Además, los campamentos nacionales y estatales son ejemplos de deliberación y organización del movimiento. La principal herramienta de organización son las células que funcionan en cada frente de actuación del movimiento, su objetivo es establecer un canal de diálogo entre los jóvenes de sus territorios, para que permita a la LPJ conocer mejor a los jóvenes, su realidad, buscando una forma más efectiva de incluir la juventud en la lucha social. Existe una profunda relación en el hacer y construir el movimiento con la forma de ser juvenil, conjugando el lúdico, irreverencia, creatividad, así como el compromiso político de mantener una organización social de la juventud. El LPJ se identifica como un movimiento social de/con juventud, que agrupa a jóvenes de diferentes territorios y que, en el contexto de su acción política, se ha puesto en el escenario produciendo nuevas prácticas y formas de hacer, a las que llamamos actividades educativas.

Palabras clave: Movimientos Sociales. Levantamiento Popular de la Juventud. Juventudes.

\section{Introdução}

Investigar o significado da palavra "levante" nos conduz a diversas acepções: é ação, é mover-se, é levantar, é erguer, é elevar, é insurreição, é rebelião - o Levante Popular da Juventude (LPJ) é tudo isso. Por isso mesmo, a melhor forma de conhecer o LPJ é observar sua performance, seu ritmo, sua cadência, seu movimento nas manifestações de rua.

Neste artigo, pretendemos apresentar um recorte da pesquisa ${ }^{1}$ que discute sobre o Levante Popular da Juventude (LPJ) no estado do Ceará com todas suas vibrações e gestualidades, como um corpo em movimento.

Estudar juventude e movimentos sociais é antes de tudo uma oportunidade de saber mais sobre os(as) jovens a partir dos seus movimentos. Nosso interesse é abrir um campo de discussão sobre essa juventude que observamos e interagimos no contexto de nossos trabalhos, pois acreditamos que "a investigação científica jamais se fecha sobre si mesma, como num circuito, tornando-se definitiva, mas opaca. Os resultados que procura obter autenticam-se mais pelos horizontes que descortinam do que pelas 'verdades' que contém” (FORACCHI, 1977, p. 6).

Desse modo, consideramos que a juventude é uma condição histórica e social fabricada pelas determinações do seu tempo presente e sujeita às mudanças (de sua própria condição), econômicas, do mundo do trabalho, sociais e geopolíticas de cada momento histórico.

1 Pesquisa de doutorado realizada no Programa de Pós-Graduação em Educação da Universidade Federal do Ceará - UFC. A tese foi defendida em 2019, intitulada A cabeça pensa onde os pés pisam: movimentos juvenis e práticas educativas emancipadoras no Levante Popular de Juventude, de autoria de Jaiane Araujo de Oliveira, orientada pela professora Celecina de Maria Veras Sales. 
Os(as) jovens estão inseridos num processo de múltiplos pertencimentos, uma vez que suas identificações estão vinculadas com suas experiências entre seus pares, com a escola, a família, o grupo de amizade e a própria sociedade em que estão inseridos(as). Os seus processos educativos, por exemplo, apontam para múltiplos direcionamentos dependendo de cada percurso.

O envolvimento social não é, portanto, resultante de escolhas individualizadas, nem tampouco prescinde da escolha de cada um na adesão ou permanência a determinada rede de relacionamentos. Os sujeitos se integram na sociedade através de interconexões ramificadas. (CARRANO, 2003, p. 155-156).

Com as constantes transformações ocorridas na sociedade, especialmente no mundo do trabalho, no processo de escolarização, na família, na política e na economia, cada vez mais percebemos a necessidade de pensar a juventude a partir de suas relações e contextos, pois a própria concepção sobre o que é ser jovem passa a ter desdobramentos diversos.

Com toda essa variedade de percursos e experiências vividas, não é possível pensar numa linearidade quando se pensa nessa juventude. Nesse sentido, "o jovem é o que ele é no seu presente e na sua experiência; é necessário compreender suas narrativas e práticas no seu cotidiano atual, e não concebê-lo como um devir para o futuro mundo adulto" (STECANELA, 2008, p. 90).

Os interesses e aspirações juvenis são múltiplos, o que nos orienta a compreender que os(as) jovens estão em um processo relacional com sua dimensão individual e coletiva. Dessa forma, eles(as) são afetados(as) por diversas determinações que envolvem o local e o global, o micro e o macro, o individual e o coletivo. Portanto, expressamos a nossa intenção de compreender a juventude em sua unidade e sua diversidade, de modo relacional, em suas múltiplas tramas sociais.

Tem esse elemento, da própria tradição da esquerda de se compartimentar, de ter as categorias, não sei o que, pá. Mas também tem um processo pra gente da juventude que a própria juventude é colocada em caixinha. Então, a gente cresce ouvindo falar que tem 'ah, a tribo do esquete e a tribo do surf não se falam, se odeiam e não sei o que’ e são coisas completamente diferentes, e ai tem os time das patricinhas, não sei o que, do hip hop, a galera... enfim, a gente cresce também com essa coisa das tribos separada que também é uma ferramenta importante de dominação, a gente entende, de quanto mais fragmentada mais fácil dominar. E o que a gente pensa sobre a juventude? A gente consegui no movimento identificar questões que são comuns e trabalhar em cima delas. Então, quando a gente olha, por exemplo, eu moro em Fortaleza então tenho mais facilidade de enxergar as frentes estudantil e territorial. (Tamires, 28 anos, LPJ).

Os(as) jovens militantes constroem saberes, experiências e ação política dentro do LPJ mediante o que eles(as) dizem e fazem dentro do movimento e em movimento. O LPJ se apresenta como um movimento social de/com juventude, que reúne jovens de territórios distintos e que, no contexto de sua ação política, têm se colocado em cena, produzindo novas práticas e modos de fazer, os quais denominamos de atividades educativas.

\section{Um movimento social de juventude: LPJ}

As transformações na geopolítica mundial impostas pela globalização e pelo sistema capitalista e o aumento da concentração de riqueza e, consequentemente, da violência anunciam a emergência ou renovação dos sujeitos sociais em cena. Os movimentos já não têm mais uma única cara, um único rosto, as demandas são plurais, múltiplas, assim, em suas práticas e formas organizativas, mudam, trazem o elemento das tecnologias como aliado nesse contexto de renovação e desenham novos repertórios de resistência. Segundo Sales (2018), é também diante do panorama de golpe e opressão que renasce o sentido dos verbos ocupar e resistir. 
O LPJ surge com o desejo de organizar a juventude do Brasil. Os desdobramentos das análises realizadas por alguns movimentos sociais, em especial, os ligados à Via Campesina ${ }^{2}$, desde os anos de 1990, contribuíram para um diagnóstico: faltava uma organização social, política e urbana específica, que fosse dirigida pelos(as) jovens, com os(as) jovens da classe trabalhadora e que atendesse toda a juventude que estivesse interessada em participar:

O campo político que gestou esta construção foi o da Via Campesina. Desde o final dos anos 1990 percebia-se a necessidade de fortalecer o processo de organização da juventude dentro dos movimentos sociais camponeses, na perspectiva da formação de uma nova geração de militantes. Deste modo, no início dos anos 2000, os movimentos sociais que compõem a Via Campesina fortalecem processos organizativos dos seus jovens, de modo que pudessem mobilizar outros jovens para construção de um novo movimento de juventude. (LPJ, 2018).

Durante as conversas e em eventos, observamos que a temática acerca do surgimento do LPJ assumia conotações variadas. Os discursos não seguem uma narrativa única, até porque os(as) jovens sabem desse histórico a partir de um outro jovem que está no Movimento há mais tempo. Contudo, todos(as) os(as) jovens afirmam que o LPJ nasceu no estado do Rio Grande do Sul. Ao resgatarmos a trajetória do LPJ, a experiência do Rio Grande do Sul e o Acampamento Sepé Tiarajú, em São Gabriel, sempre são colocados como ponto de partida.

No ano de 2005, a Consulta Popular ${ }^{3}$, instrumento político de referência para grande parte dos quadros da Via Campesina, decide, em Assembleia Nacional,

Organizar a juventude da classe trabalhadora e, em especial, os jovens, da periferia urbana. A leitura da Consulta era de que seria indispensável para a construção de um projeto contra hegemônico no Brasil a inserção na juventude trabalhadora, principalmente nas massas das grandes periferias. Era, portanto, necessário deslocar quadros de um contexto onde havia um razoável processo de organização, para construir força social nos centros urbanos, onde este campo político, bem como as demais organizações de esquerda, tinha uma força muito residual. (CADERNO DEBATE, 2018, LPJ).

O LPJ se coloca como um movimento social de juventude com a intenção de juntar/organizar os jovens em seus diferentes espaços e contextos. Sua origem é resultado de um processo de reflexão de alguns movimentos, entre eles o Movimento dos Trabalhadores Rurais sem Terra (MST), o Movimento dos Atingidos por Barragem (MAB), as Pastorais de juventude, vinculadas à Consulta Popular. Dessa forma, o Levante surge a partir do interesse de um grupo de organizações que recobre um campo político, em juntar os(as) jovens em um Movimento organizado para pensar em uma sociedade em que os jovens pudessem discutir suas demandas e necessidades.

No Rio Grande do Sul, constitui-se um grupo de trabalho para efetivar a construção de uma organização de juventude. Naquele momento, ainda não existia um formato de como deveria ser a organização, sua consigna, sua organicidade, sua concepção e o próprio fazer político. Na verdade, todos esses aspectos têm se definido ao longo do processo de afirmação do LPJ enquanto Movimento Social.

\footnotetext{
2 A Via Campesina nasceu em 1992, quando várias lideranças camponesas dos continentes americano e europeu, que participavam do II Congresso da Unión Nacional de Agricultores y Ganaderos de Nicarágua (Unag), realizado em Manágua, propuseram a criação de uma articulação mundial de camponeses. É uma organização mundial que articula movimentos camponeses em defesa da agricultura familiar em pequena escala e agroecológica para garantir a produção de alimentos saudáveis. Entre seus objetivos, constam a construção de relações de solidariedade, reconhecendo a diversidade do campesinato no mundo; a construção de um modelo de desenvolvimento da agricultura que garanta a soberania alimentar como direito dos povos de definirem suas próprias políticas agrícolas; e a preservação do meio ambiente, com a proteção da biodiversidade (DICIONÁRIO DA EDUCAÇÃO DO CAMPO, 2012, p. 765).

3 Surgiu em 1997, impulsionada pelos movimentos sociais, principalmente o MST. É uma organização política, mas não partidária. Tem investido no trabalho de formação de base com o intuito de formar a militância para uma proposta de sociedade em que o povo possa participar diretamente e decidir acerca de seus interesses.
} 
Durante os espaços em que acontecem os eventos, ou mesmo nas conversas informais e entrevistas, os(as) jovens colocam que o movimento está em processo de construção e que muitas coisas têm sido definidas no terreno da prática, do fazer o movimento; é a partir de um processo reflexivo e avaliativo que eles têm encontrado os caminhos que sustentam e dão direção para a afirmação do Movimento.

Para compor essa discussão acerca da caracterização do LPJ, tomamos como recurso as narrativas dos jovens, nas entrevistas que concederam, e alguns documentos confeccionados por eles(as) e entregues nos dois acampamentos, a saber: nacional e estadual. Realizamos ainda uma pesquisa bibliográfica em teses, dissertações, artigos científicos publicados sobre o LPJ, mas não encontramos nenhum trabalho sistematizado que trouxesse essa discussão histórica sobre o Movimento.

As primeiras atividades realizadas no sentido de organizar efetivamente o LPJ têm início em 2005, com a participação de um pequeno grupo de pessoas ligadas à Pastoral da Juventude Rural e ao Movimento dos Trabalhadores Rurais Sem Terra. Esse grupo inicia as primeiras experiências de organização da juventude nas periferias de Porto Alegre/RS, a partir da realização de encontros, reuniões e trazendo os problemas vivenciados pela juventude como centro da discussão. O nome Levante Popular da Juventude surge de modo espontâneo, durante a apresentação da proposta do Movimento em uma escola na periferia de Porto Alegre, no Morro de Santa Tereza.

Nossos jovens eram muito ligados às pastorais e construíram o Levante muito no sentido de dialogar com aquela juventude e construir um instrumento alternativo de vida mesmo. E aí foram feitas várias iniciativas lá em Porto Alegre. Tanto na questão do hip-hop, como na questão da cultura, da dança e aí foi uma coisa que deu bastante certo o Levante no Rio Grande do Sul, porque parte do acúmulo nosso campo tinha, mas a gente precisava construir um instrumento de juventude de novo tipo. (Miguel, 24 anos, LPJ, 2015).

Quando os(as) jovens falam de um Movimento de "Novo Tipo", eles colocam que suas experiências, até então em movimentos de juventude, coletivos de juventudes, eram muito limitadas no que se refere ao seu campo de atuação. Dessa forma, o Levante tinha a pretensão de ser um Movimento que acolhesse toda a juventude, de todos os espaços da cidade e do campo. O novo está ligado às práticas que o LPJ tem elaborado para realizar a ação política entre os(as) jovens.

Dentro do LPJ, observamos processos de mutações/transformações no que se refere às suas ações coletivas, que, por ora, se misturam com os modos de fazer tradicionais, mas que são ampliados a partir da criação de novos modos de se colocarem em cena, assim, reconhecem que não se trata de fazer rupturas, tampouco acreditar em formatos lineares e fixos, mas de encontrar um ponto de equilíbrio entre o que já foi herdado com a capacidade de produzir nossas expressões juvenis na política. "Sociedades concretas combinam formas de ação que nascem de datas e temporalidades diversas - elas estão estratificadas em termos de diferentes camadas históricas" (MELUCCI, 2001, p. 18).

Sou estudante, estou na rua, estou no Levante, vim aqui denunciar que no Brasil ainda existe a ditadura militar, enquadro, baculejo, repressões sociais, isso tudo é herança do tempo dos generais, pula, pula quem é contra a ditadura, pula sai do chão quem é contra a repressão. (Canção do Encontro de História).

A canção em destaque expressa o engajamento dos jovens durante um evento de formação organizado pela Federação do Movimento Estudantil de História (FEMEH). Em 2009, vários jovens que construíam o LPJ, em Santa Maria, Rio Grande do Sul, vieram participar do encontro de História no Ceará. A partir desse encontro entre os(as) jovens do Ceará com os do Rio Grande do Sul, inicia-se o processo de fundação do LPJ no estado do Ceará.

Nesse processo 2006, 2007, 2008 fui morar em Santa Maria, e essa relação começa com o Ceará. Eu era estudante de história, o nosso povo daqui, do Ceará, também construía a Federação do 
Movimento Estudantil de História, FEMEH. Em 2009 por iniciativa, inclusive, dos contatos que a gente tinha com o campo, com a consulta, juntamos aqui um seminário de formação da FEMEH. Nesse seminário de formação nós lá em Santa Maria, eu já morava lá, construindo o Levante em Santa Maria, nós fomos para o Ceará porque a FEMEH estava defendendo um projeto popular e daí a gente sabia que tinha os nossos que estavam construindo. A gente veio para o seminário de formação aqui, foi de ônibus de Santa Maria para Florianópolis e de lá pegamos um ônibus, pegando gente de todo Brasil até chegarmos no Ceará. Daí que a gente começa. Porque quando eu cheguei aqui no Ceará já tinha toda uma mística da construção do Levante, depois a gente soube "oh, um militante do Levante está vindo para cá" e ai já foi uma relação que a gente começa a costurar na relação Rio Grande do Sul/Ceará, antes mesmo de outros estados definirem, Ceará é um os primeiros estados que três anos antes do processo de nacionalização estava muito convencido de construir essa ferramenta. (Rodrigo, 27 anos, LPJ, 2018).

No Ceará, os(as) jovens que pertenciam ao curso de História da Universidade Estadual do Ceará - UECE - foram os que estiveram à frente no processo de fundação do LPJ. Na UECE, alguns desses jovens já pertenciam a um coletivo estudantil juvenil chamado Canto Geral:

Em 2012 quando a gente faz o nosso primeiro acampamento nacional que dá 1000 jovens de todo estado, inclusive gente aqui da UECE foi, o Alan, Tiago, a Tamires que estudava história aqui na UECE que hoje é coordenação nacional. Foram para esse acampamento e trouxeram para o Ceará essa semente, essa ideia de organizar a juventude. Aqui já era organizado um coletivo chamado Canto Geral. Aí o pessoal do Canto Geral que foi para o acampamento trouxe essa ideia e se tornou e construiu o Levante aqui no Ceará. A gente fala que a UECE é o berço do Levante aqui no Ceará. Porque foram as pessoas daqui que foram, que trouxeram essa ideia e aí a gente está em todas as regiões, não em todos os municípios porque o Ceará é grande e a gente tem nossas limitações. Mas a gente está em todas as regiões. Região Sul, ali Quixadá, Sobral, a gente agora está no processo de construir em Icapuí, Prainha do Canto Verde, mais no litoral. Mais a gente já é bem interiorizado. E aí a gente vem para o Ceará, faz o nosso acampamento estadual aqui na UECE, o primeiro acampamento estadual foi aqui. (Fernandinha, 24 anos, LPJ).

Dessa forma, o processo de construção do LPJ, aqui no Ceará, se inicia no ano de 2009 a partir da mobilização da Frente Estudantil, mas logo começa a chegar até os jovens da Frente Territorial.

Já estava muito convencido de ter essa ferramenta, que vai para além do movimento estudantil, que consiga organizar o jovem da periferia, que dialogue com essa questão da agitação e propaganda, essa relação da cultura, da política, estava muito convencido disso em 2009. Em 2010 acontece o encontro nacional aqui, dos estudantes de história, lá na UECE, que era onde nosso povo já tinha uma boa inserção. E já começa também ai, fizemos um ato. Um ato com muita agitação política, oficinas de preparação, tudo que é a cara do Levante com stencil, com teatro, com música, música que depois o próprio Levante incorporou, era sobre a questão sobre a ditadura, porque nessa relação também tinha a pauta do movimento estudantil de história que era a abertura dos arquivos da ditadura. E essa é uma pauta que depois o Levante... é a grande bandeira de luta que a nacionalização do acampamento, a luta que nacionaliza de fato, coloca o Levante para fora é a questão dos crimes da ditadura, da denúncia, do escracho aos torturadores, a luta pela comissão nacional da verdade. (Rodrigo, 27 anos, LPJ).

A fala do jovem expressa essa relação direta entre arte e política, ou seja, a capacidade que a dimensão artístico-cultural possui de atrair, seduzir e encantar os jovens para a organização social. No Ceará, particularmente, aconteceram sucessivos eventos que impulsionaram e deram força ao processo de construção do Levante no estado. Além do evento realizado pelo curso de História, no qual vários estudantes assumiram a militância do Movimento, em outubro de 2011, quando aconteceu o Festival Latino-Americano da Juventude em Fortaleza, vários estudantes que vieram de outros estados se encontraram com jovens aqui do Ceará e debateram sobre a construção do LPJ. 
Antes de firmar sua fundação, o LPJ já vinha em um processo de busca por um caminho organizativo.

Então, é um processo. Inclusive a forma como a gente se organiza, tipo, esses seis anos antes de oficializar a nacionalização a gente experimentou diversas formas organizativas, momentos de construir plenárias, coordenação, coordenação política. O Levante é isso, tipo assim, ele meio que aproveitou muitas oportunidades, digamos assim, teve muitas parcerias em eventos que não eram necessariamente ainda do Movimento, mas que vocês chegaram juntos, estiveram presentes para inclusive para divulgar quem era, como se organizava, o que estava querendo. (Rodrigo, 27 anos, LPJ).

O interesse em fundar o Levante no Ceará foi ganhando mais força pelo número de jovens que chegavam e pelas experiências vivenciadas pelos jovens cearenses em outros eventos do Levante no Rio Grande do Sul, como o Acampamento Nacional de 2012. O primeiro acampamento Estadual do Levante/Ceará aconteceu em 2013, em Fortaleza, na UECE, e recebeu o nome de Acampamento Frei Tito ${ }^{4}$. O acampamento reuniu em média 1500 jovens de várias cidades do Ceará. No ano de 2018, aconteceu o segundo acampamento estadual na cidade de Caucaia. Estiveram presentes jovens de 80 municípios do estado.

Nos dois acampamentos (nacional e estadual) em que estivemos presentes, pudemos vivenciar momentos de muita troca, aprendizados e reflexão sobre as movimentações dos(as) jovens no LPJ. São espaços de muita participação, nos quais é possível perceber a capacidade criativa e diversa dos(as) jovens, a qual se expressa pelas suas diferenças étnicas, sexuais, de gênero, culturais, territoriais, econômicas e sociais.

O acampamento é um espaço que possibilita ampliar o olhar para a realidade e as heterogeneidades juvenis. Dessa forma, se instaura como um campo rico e fecundo ao exercício do pensamento investigativo, são diversas as movimentações juvenis, as diferenças culturais, de orientação sexual, os modos de ser e estar no mundo. É um espaço no qual se cultivam outras formas de sociabilidade mediada pela participação e pelo engajamento coletivo que se expressa em todo o evento, no cuidado com o outro, garantindo segurança, alimento, proteção, acolhimento e afeto. Dentro dos espaços realizados pelo LPJ, é visível a política com afeto e o corpo a corpo, que revelam a relação entre a política e o afeto, conforme destaca o autor:

Construir vínculos políticos é indissociável da capacidade de ser afetado, de ser sensivelmente afetado, de entrar em um regime sensível de aisthesis. As metáforas do corpo político não descrevem apenas uma procura de coesão social orgânica. Elas também indicam a natureza do regime de afecção que sustenta adesões sociais. Há certas afecções orgânicas, e não 'deliberações racionais', que nos fazem agir socialmente de determinada forma. Pois um corpo não é apenas o espaço no qual afecções são produzidas ele também é produto de afecções. As afecções constroem o corpo em sua geografia, em suas regiões de intensidade, em sua responsividade. (SAFATLE, 2012, p. 23).

Ouvir e dar espaço para que eles(as) possam se mostrar, se expressar, já que muitas vezes isso é negado do lado de fora, faz com que, ali, no acampamento, encontrem um alento para expressar sua condição humana e, nesse experimentar, tornam-se também mais humanos na medida em que reconhecem no outro o sentido de sua humanização.

\footnotetext{
4 Frei Tito de Alencar Lima foi um frade católico cearense. Assumiu a direção da Juventude Estudantil Católica em 1963 e foi morar em Recife. Mudou-se para São Paulo para estudar Filosofia na Universidade de São Paulo (USP). Em 1968, foi preso por participar do XXX Congresso da União Nacional dos Estudantes (UNE) em Ibiúna (SP). Fichado pela polícia, tornou-se alvo de perseguição pela repressão militar. Preso em novembro de 1969, em São Paulo, acusado de oferecer infraestrutura a Carlos Marighella, Tito foi submetido à palmatória e choques elétricos no Departamento de Ordem Política e Social (DOPS). Na prisão, escreveu sobre a sua tortura. O documento correu pelo mundo e se transformou em símbolo da luta pelos direitos humanos.
} 
O LPJ, no plano nacional e estadual, incorporou a dimensão da agitação e propaganda, a Agitprop5. A Agitprop se constitui em uma linha de atuação da organização do LPJ. Atualmente, existe um coletivo nacional de agitação e propaganda o qual tem direcionado as atividades do movimento no que se refere à arte, à cultura e à batucada.

A Agitprop é a nossa maior marca: são as armas que escolhemos para dialogar com a sociedade e mostrar os desejos da juventude. Nossa agitação busca traduzir nossas ideias numa mensagem simples e que atinja muitas pessoas. Já a propaganda é mais profunda: se refere ao processo de espalhar a reflexão sobre a luta de classe para os jovens. Ações de agitação e de propaganda estão sempre interligadas. Como fazemos isso na prática? Com grafite, muralismo, teatro, batucada, ocupações de ruas e o que mais nossa criatividade permitir. (LPJ, CADERNO DE DEBATE 1, 2016).

O caráter interventivo de suas ações se afirma no interior das manifestações tradicionais de rua. Durante os escrachos, os jovens se dirigem ao local onde vive ou trabalha alguém que representa uma ameaça à sociedade (pode ser um torturador, um político corrupto) e o denunciam publicamente: "Se não há justiça, há escracho popular", define uma das máximas da organização. Reiteram que não pretendem substituir o aparato estatal, e sim tornar pública uma situação desconhecida pela maioria da população.

O LPJ organiza a juventude a partir de três frentes/campos que são na verdade os territórios em que vivem esses(as) jovens. Os(as) jovens da periferia são classificados em jovens da Frente Territorial; os(as) jovens que estão nas universidades (públicas e privadas), de Frente Estudantil; e os(as) jovens que estão no campo são denominados de Frente Camponesa.

Durante a pesquisa, percebemos a presença de poucos jovens da Frente Camponesa nos eventos e espaços organizados pelo LPJ. Durante as entrevistas, essa observação foi confirmada, pois os(as) jovens colocaram que a mobilização com os jovens da Frente Camponesa ainda estava sendo construída, uma vez que, em áreas de assentamento, por exemplo, onde inicialmente seria o alvo do LPJ, os(as) jovens já participavam de outros movimentos sociais, como o MST e o MAB.

A discussão que se levanta nesse aspecto é de pensar os limites e o alcance que cada organização possui. No discurso de alguns jovens, ficava claro que, na tentativa de buscar um caminho no que se refere ao processo de organização do LPJ em seus campos de atuação, ocorria uma espécie de "brecha" nos próprios espaços do MST, uma vez que nem todos(as) os(as) jovens de áreas ocupadas pelo MST, por exemplo, conseguem estabelecer uma relação identitária com o Movimento. Dentro desse terreno de ambiguidades, acordos e ajustes, o LPJ tem interpretado isso como uma "porta entreaberta", em que é possível estabelecer um diálogo com esses jovens ainda não vinculados diretamente com uma organização social.

Quando o Levante chega é como se o Levante levasse uma outra visão do MST para esses jovens, então eles se interessam no levante, "massa, tem jovem, tem jovem", mas eles também veem que a luta do MST também é deles, tanto que eles têm um coletivo de juventude do MST que também é super parceiro do Levante. E assim, pelo o que eu vejo a gente tem conseguido construir junto, a gente tem conseguido caminhar junto tanto a juventude do levante como a juventude do MST. (Fernandinha, 24 anos, LPJ).

A narrativa da jovem é reveladora de um aspecto importante identificado neste trabalho, que está relacionado ao jeito de fazer, de se colocar em cena e anunciar o discurso, a linguagem, assim como tantos outros dispositivos que acionam a ação política, se afirmando como elemento

5 A expressão "Agitprop" foi criada por militantes políticos da Rússia, no ano de 1917, no sentido de definir os diferentes modos de fazer a agitação popular e, ao mesmo tempo, divulgar os projetos políticos do partido Bolchevique. 
fundamental o qual contribui para que os(as) jovens desejem estar organizados e participando das questões da sociedade, do Assentamento, da universidade/escola e da periferia. Na única entrevista que conseguimos realizar com um jovem da Frente Camponesa, ele destacou o que motivava seu interesse em participar do LPJ.

Eu tenho muito interesse em entrar no Levante, porque ele é meio diferenciado, ele é diferenciado, porque eles são pessoas abertas, são vários tipos de cultura e eu gosto muito dessas coisas que eles fazem, das festas, do Rap que fala da realidade brasileira. Agora, eu estou tentando entrar também no MST para entrar no Levante mais para frente se Deus quiser! O MST é diferenciado porque é mais palestras, discussões, grito de ordem, reuniões, é mais explicando o que é a política. O LPJ é diferenciado porque vai para as ruas e tem a forma deles de se expressar, de lutar. O levante é mais animado, é mais auto astral, tem várias culturas de músicas, tem o batuque. (Pedro Henrique, 18 anos).

Esse discurso expressa a importância que o jovem atribui às expressões artísticas, ao lúdico e à arte como possibilidade de resistência e ação política.

Na verdade, nas representações correntes da juventude, os jovens são tomados como fazendo parte de uma cultura juvenil «unitária». No entanto, a questão central que se coloca à sociologia da juventude é a de explorar não apenas as possíveis ou relativas similaridades entre jovens ou grupos sociais de jovens (em termos de situações, expectativas, aspirações, consumos culturais, por exemplo), mas também - e principalmente - as diferenças sociais que entre eles existem. (PAIS, 2003, p. 140).

Durante o processo de inserção, observamos que os(as) jovens vão construindo seus códigos de filiação transcendendo seus limites geográficos, porque, no fundo, o que eles(as) buscam é encontrar sentido e atribuir sentido às experiências que estão vivendo, seja no campo da arte, da política e da própria existência humana.

Ao se colocar disponível e aberto aos murmúrios e gritos da juventude, o LPJ passa a ser interessante para os(as) jovens. Desse modo, não é o LPJ isoladamente que tem atraído os(as) jovens, mas o jeito que vem construindo, de se colocar em cena, incentivando os(as) jovens a serem portadores da ação juvenil na política. No momento em que acolhe as diferenças, suas expressões artísticas e culturais possibilitam lidar com a diversidade como um elemento positivo e rico que é fecundo e essencial para o campo político.

Essa concepção está diretamente alinhada com a ideia de que, somente na presença de outros e com os outros, os(as) jovens podem realizar e fazer-se na ação política. Arendt $(2003,2010)$ afirma que a política, para acontecer, necessita da presença do outro, mas, sobretudo, de uma relação com os outros, por isso ela insiste tanto no diálogo como elemento mediador da política.

Na medida em que amplia o campo de visão para compreender quem são os(as) jovens que chegam ao movimento, o LPJ percebe que estes lidam de forma variada com seus corpos, sexualidade e individualidade, e que tudo isso pode ser aproveitado como potência para dentro do movimento. Com isso, é possível mesclar velhas práticas de fazer política com novas formas, revestidas de caráter cultural e simbólico da força juvenil.

Nos últimos anos, e de forma cada vez mais intensa, podemos observar que os jovens vêm lançando mão da dimensão simbólica como a principal e mais visível forma de comunicação, expressa nos comportamentos e atitudes pelos quais se posicionam diante de si mesmos e da sociedade. É possível constatar esse fenômeno nas ruas, nas escolas ou nos espaços de agregação juvenil, onde os jovens se reúnem em torno de diferentes expressões culturais, como a música, a dança, o teatro, entre outras, e tornam visíveis, através do corpo, das roupas e de comportamentos próprios, as diferentes formas de se expressar e de se colocar diante do mundo. (DAYRELL, 2003, p. 119). 
Mais do que buscar juntar os(as) jovens em uma organização social, o LPJ coloca o desafio de estabelecer uma compreensão que trate dos processos comuns que atingem a sociedade brasileira em sua estrutura macrossocial e política, cultural, aliado às especificidades de cada território e de sua cultura juvenil. Por isso mesmo as temáticas que envolvem a democracia, a participação, a formação e a ação social dos indivíduos ganham centralidade nos debates e eventos realizados pelo Movimento.

Os(as) jovens demonstraram, durante esta investigação, que a atuação do LPJ, na Frente Camponesa, ainda é um caminho a ser traçado. Se, no primeiro momento, as linhas desenhadas pelo LPJ em direção aos(às) jovens que poderiam compor a Frente Camponesa estariam ligadas a outros movimentos/organizações, o que poderia acarretar o risco em disputas entre as organizações, hoje o LPJ traça outras rotas para dialogar e organizar a juventude do campo para dentro do LPJ. Na análise do movimento, seriam aqueles(as) que vivem no campo, mas ainda não estão organizados.

Os(as) jovens trazem as especificidades de cada frente. A Frente Estudantil, por exemplo, se apresenta como uma das mais organizadas. São jovens que, mesmo pertencendo à classe trabalhadora, possuem mais acesso e oportunidade de inclusão social.

Sabemos as especificidades do jovem da academia, mesmo ele vindo de uma classe trabalhadora é diferente, ele já conseguiu romper umas barreiras que o jovem da territorial não conseguiu. Ensino fundamental, ensino médio, ensino superior já dá uma consciência mais elevada, que consegue pagar seu transporte, que consegue ter um alimento dentro da universidade, uma bolsa talvez e essas características como próprio jovem trabalhador, no plano geral. (Babau, 29 anos, LPJ).

Ocupar o espaço da universidade (ensino superior) é um salto muito significativo para os(as) jovens, pois isso representa romper muros que historicamente vêm sendo edificados contra os(as) jovens da classe trabalhadora, a qual mora na periferia das cidades ou mesmo nas zonas rurais. $\mathrm{O}(\mathrm{a})$ jovem militante que ocupa a universidade institui não só sua presença física, mas toda sua história e a experiência de quem conseguiu, com todas as dificuldades, ir além do que tinha sido traçado para eles(as), com isso rompe os muros da desigualdade, da falta de oportunidade e da exclusão. Sua inserção possibilita a oportunidade em aprender outros conhecimentos, conhecer novas pessoas, ampliar a rede de amizades, afeto e identificação, embora, para alguns jovens, romper as barreiras da desigualdade ainda se apresente como um desafio complexo.

Para os(as) jovens da Frente Territorial, o primeiro desafio é buscar condições em que possam se alimentar, ter dinheiro para a passagem, para se movimentar na cidade e poderem participar das atividades do Movimento. "Nós sabemos os limites do jovem da Territorial, que às vezes não tem dinheiro da passagem para vir para a reunião e, muitas vezes, nem o que comer, nós sabemos essa situação de violência que vive o jovem da Territorial" (Babau, 29 anos).

Neste trabalho, a categoria de território é compreendida como mais do que um lugar de produção, ou seja, como um espaço de criação político-cultural. "O território é, então, o espaço onde se desenvolvem relações sociais diferentes das capitalistas hegemônicas, aqueles lugares onde os coletivos podem praticar modos de vida diferenciados" (ZIBECHI, 2015, p. 39). Não se trata de afirmar que estes vivem apartados do modelo de produção e reprodução da vida social capitalista, mas de compreender que outras formas de vida são possíveis, baseadas em novas formas de pensar, se organizar e produzir a existência humana, nesses espaços em que denominamos de "Territórios em Resistência” (ZIBECHI, 2015).

A resistência juvenil nem sempre é uma escolha, às vezes, diante das situações adversas que eles(as) enfrentam diariamente, a resistência é a única alternativa. Desse modo, a resistência passa a ser a condição para os(as) jovens contornarem as barreiras mais imediatas, como a de se deslocar de um ponto a outro da cidade, sair de suas casas para participar das atividades do movimento e, quem sabe, nessa forma de resistência, encontrar uma alternativa de existência mais humana. 
O LPJ vem buscando construir sua organização a partir de diversos setores. A principal ferramenta de organização são as células, as quais funcionam em cada frente de atuação do movimento. Seu objetivo é estabelecer um canal de diálogo entre os(as) jovens de seus territórios, de modo que isso possibilite ao LPJ conhecer melhor os(as) jovens, sua realidade, buscando uma maneira mais efetiva de incluir a juventude na luta social. Com isso, pretende também se multiplicar, criando várias células em seus espaços de atuação.

A gente se organiza primeiro a partir de células, então em cada lugar de atuação tem as células. Então cada célula tem coordenação e aí cada coordenação forma uma operativa. Aqui na UECE a gente tem uma célula, tem a coordenação da célula que forma o grupo de coordenadores e tem a operativa da UECE, operativa e coordenação é quase a mesma coisa (Fernandinha, 24 anos, LPJ).

A célula é o primeiro espaço de acolhimento aos jovens. Nela, é possível conviver, interagir e manter uma relação mais próxima dos(as) jovens, experiência que permite ao LPJ e aos(às) jovens entre si enxergarem as dificuldades e os problemas que estão enfrentando em sua realidade juvenil.

A gente faz reunião toda semana, todas terças nós nos reunimos. Essas reuniões começaram nas pracinhas mesmo da Caucaia. Aí dentro dessas reuniões nós marcamos nossas atividades de acordo com a nossa realidade. Às vezes a nossa turma está muito vulnerável no sentido mais psicológico, a turma as vezes está ruim, está na bad e aí a gente tem que procurar também esse auxílio para os nossos militantes, a gente precisa muitas vezes procurar redução de danos para a nossa turma aqui da periferia. Então, a gente vai trabalhando de acordo com a nossa realidade. Vamos promovendo debates sobre a questão urbana, a violência que a gente sofre todo dia, todos os direitos são negados para a gente. Então a gente busca trazer esses debates que cabem dentro da nossa realidade. A gente também debate sobre negritude, sobre as lutas das mulheres, a luta LGBT e aí a nossa juventude vai se identificando com essa luta. (Pam, 27 anos, LPJ).

Para o movimento, a célula é o instrumento da organização que garante a unidade e o pertencimento do grupo em defesa das lutas dentro das células. A célula está presente em todas as frentes (Territorial, Camponesa e Estudantil) e o seu principal objetivo é formar pequenos grupos com atuação constante em seus territórios, a partir de reuniões periódicas e com coordenação própria, para que, assim, cada célula possa dialogar melhor com os jovens de cada território, uma vez que as necessidades e as lutas enfrentadas em cada espaço desse são diferentes. Em entrevista realizada com um jovem militante do Levante, ele explica melhor como funciona a célula:

A gente se organiza, nós temos um modelo orgânico a nível nacional que foi acumulado nesses últimos anos, é uma estrutura orgânica que ela começa nas células, que são grupos de bases, tem organização que chama de núcleo, de grupo. A gente chama de célula! Então são os nossos núcleos de base, digamos assim. Nosso grupo de base que aí dentro da célula você pode ter diversas células que você pensar, tanto na universidade, como a célula do hip-hop, a célula do bairro que é nossa frente territorial. Qual o sentido da célula? É está dentro do seu local de atuação. Então eu tenho que está dentro da célula que é meu local de atuação. São grupos pequenos que se organizam a partir do seu local de atuação para pensar intervenção de dois tipos: como melhorar seu local de atuação, mais como trazer mais jovens. Então a gente se organiza a partir dessas células que tem os seus representantes, os seus coordenadores. Toda célula tem, hoje, um representante, um coordenador que aí a gente estrutura, que é uma estrutura horizontal, só que ao mesmo tempo com um comando, tem as suas coordenações e aí em nível de estado tem a coordenação estadual que é com representação dessas células. (Miguel, 24 anos, 2015). 
Além das células, o LPJ possui uma secretaria operativa que fica responsável pelas atividades de infraestrutura. Em um acampamento, seminário, os jovens que compõem essa secretaria se envolvem com tarefas de conseguir cadeiras, material de mística, produtos de higiene, som e tudo que envolve a realização dos eventos.

Essa pessoa na operativa vai ser o link com as decisões que vêm da nossa coordenação nacional que se reúne periodicamente em São Paulo. A coordenação reúne lá, a demanda vem para a operativa e a gente repassa para a base ou então o processo inverso acontece, se a base tem alguma coisa que não gostou, a base tem alguma demanda, a gente precisa disso, precisa de determinada formação, a gente precisa organizar determinado evento ou fazer qualquer outra coisa repassam para a coordenação ou a coordenação repassa para a operativa a gente dá um repasse para a nossa coordenação nacional também para que todo mundo fique ciente das atividades que o Levante desenvolve em todo o Brasil. (Fernandinha, 24 anos, LPJ).

O modelo organizativo construído pelo LPJ é amplo e complexo, uma vez que envolve: células, secretarias, setores, coordenação estadual e nacional. Dentro dos setores, o LPJ organizou um grupo de jovens que se dividem em coletivos. Atualmente, o LPJ está organizado em quatro coletivos.

São o coletivo de agitação e propaganda, o coletivo de comunicação, o coletivo de finanças e o de formação, são quatro coletivos. Cada coletivo desse é acompanhado por um representante nacional, uma pessoa da coordenação nacional que acompanha diretamente esse coletivo. Hoje o coletivo de formação ele pensa em ter momentos de formação do estado, então é do Ceará todo. E esse coletivo tem representação daqui da UECE, representação da USP, representação daqui de Fortaleza, Sobral, do Cariri, onde a gente é mais forte. E aí esse coletivo vai pensar. O coletivo de finanças a gente ainda está caminhando; ele pensa maneiras de sustentar o movimento, da onde a gente vai tirar dinheiro para fazer as coisas, como é que a gente vai se virar. Então é esse coletivo que vai pensar isso aí. O nosso coletivo de comunicação cuida das redes sociais, dos nossos pôsteres, de tudo que gira na comunicação do Levante é esse coletivo que cuida. E aí cuida da nossa página no Facebook, nosso canal no YouTube, das páginas das regiões, tem a região norte com Sobral, Cariri. Cada Levante tem a sua página e isso tudo perpassa pelo coletivo de comunicação. O coletivo de agitação e propaganda é que cuida dos nossos instrumentos, cancioneiros quando a gente vai para as atividades, modelo de blusa, faixas que a gente faz, panfleto, esquete, qualquer coisa envolvendo a agitação e propaganda esse coletivo é responsável de fazer, de pensar. Eles sentam, chama a galera 'ah, vamos construir isso e a gente precisa disso e disso' e a gente agiliza e dá prosseguimento as atividades. (Fernandinha, 24 anos, LPJ).

Em relação às coordenações, o jovem Babau, membro da coordenação Nacional, revelou como está organizando o LPJ nos contextos estadual e nacional. Atualmente, o LPJ está inserido em 25 estados brasileiros. A mesma estrutura é replicada nacionalmente, de modo que cada estado possui três representantes, responsáveis pela composição nacional do movimento.

A coordenação nacional é definida durante os Acampamentos Nacionais, os quais são as maiores instâncias de deliberação do LPJ. Os encontros da coordenação nacional geralmente ocorrem em São Paulo, pois, segundo eles(as), é um lugar mais central para todos os demais estados. As reuniões/encontros acontecem a cada dois meses, e os coordenadores repassam os informes para os seus estados de origem. Esse modelo é copiado de outros movimentos, por exemplo, do MST, e os militantes do LPJ o destacam como herança organizacional.

Os(as) jovens do LPJ entendem que é preciso organizar a juventude, por isso trazem, dentro dessa configuração organizativa dos movimentos sociais, elementos tradicionais, mas, sobretudo parecem investir em novas possibilidades, como jeitos de fazer que possam atrair o interesse dos jovens para dentro do movimento. Com um discurso mais horizontalizado e aberto ao diálogo, afirmam que 
pretendem agregar as múltiplas bandeiras da juventude, pois passam a identificar que os modos de agir e se mover politicamente carregam marcas novas, pois são sujeitos outros que anunciam outras formas de fazer a política. Com isso, retomam o sentido de participação e de cidadania. Mas, afinal, que táticas estão utilizando no combate à exploração, à violência e à negação de seus direitos?

Esses 'novos movimentos sociais' não se organizariam em combate ao estado, nem com a finalidade de conquistá-lo. Recorrendo a formas de ação direta, 'no nível dos próprios problemas sociais', seriam agentes de pressão social, voltados para persuadir a sociedade civil. Aí está a grande contribuição de Touraine para esse debate: retomar o conceito até então um tanto esquecido de 'sociedade civil', como reino apartado do estado e do mercado, e no qual a inovação social poderia se configurar. Os movimentos sociais nasceriam na sociedade civil e, portadores de uma nova 'imagem da sociedade', tentariam mudar suas orientações valorativas. Os movimentos sociais aparecem, então, como o novo ator coletivo, portador de um projeto cultural. Em vez de demandar democratização política ao estado, demandariam uma democratização social, a ser construída não no plano das leis, mas dos costumes; uma mudança cultural de longa duração gerida e sediada no âmbito da sociedade civil. (ALONSO, 2009, p. 60-61).

Ainda pensando a partir de um recorte historiográfico, os estudos vão anunciar que o modo de tratar/reconhecer os movimentos sociais no Brasil vai mudar bastante, isso porque os Movimentos irão se organizar para manter uma estreita relação com a estrutura da sociedade. Os Movimentos ocupam as arenas de disputas, o território da cidade, a própria política, construindo outro projeto de ação; "esse projeto significa uma reforma moral e intelectual: um processo de aprendizagem social, de construção de novos tipos de relações sociais, que implicam, obviamente, a constituição de cidadãos como sujeitos sociais ativos" (DAGNINO, 2004, p. 105).

Nessa direção, é oportuno sublinhar que a realidade é dinâmica e, nessa medida, para compreendermos os movimentos sociais concretos, necessitamos, enquanto estudiosas, "captar o movimento dos sujeitos em distintas situações, fornecendo elementos a uma análise seguramente mais aproximada da realidade em que se reproduz/constrói e reconstrói o próprio movimento, suas práticas e seus saberes" (DAMASCENO, 2013, p. 4).

Historicamente temos construído um legado de manifestações, nas quais a juventude ou os estudantes foram protagonistas principais (SCHERER-WARREN, 2014), a autora ainda coloca que: "a juventude é, e historicamente tem sido, bastante idealista e, muitas vezes, quer mudar o mundo, o sistema político e relações do cotidiano. Isso não é novo, apesar de nem sempre ter tido visibilidade" (p. 4). O que a autora destaca como novo, nesse contexto de 2013, é o elemento das redes sociais como instrumentos de mobilização e convocação das massas para as ocupações de rua.

Os jovens vêm se manifestando cada vez mais pelas redes sociais, na internet, usando o suporte das novas tecnologias para se organizar. Mas isso tem sido, acima de tudo, um meio, e não explica o sentido político da ação, ou melhor, o sentido pode ser conflitivo ou antagônico numa mesma rede ou entre sub-redes, como resultante da transversalidade desse tipo de comunicação. Além disso, as redes virtuais divulgam, convocam e expressam posicionamentos, mas quase nunca possibilitam o aprofundamento do debate político, ainda que, em algumas situações, é no interior de sub-redes que interagem com outras sub-redes que mensagens conflitivas aquecem o debate. (SCHERER-WARREN, 2014, p. 420).

Portanto, o cotidiano da vida das pessoas se afirma como campo profícuo de investigação. Estar atento a essas novas formas de se organizar, de fazer política, que muitas vezes acontece no campo da micropolítica, se constitui em um ótimo exemplo de reconhecimento dos movimentos que não se deixam enganar e que insistem em defender uma sociedade na qual todos e todas tenham seus direitos garantidos. 


\section{Considerações finais}

O LPJ surge em um contexto de efervescência política no mundo e no Brasil. Onde estaria a juventude organizada do país? Acreditamos que essa indagação foi levantada pelas lideranças dos movimentos sociais ligados à Via Campesina. O início de sua construção foi marcado por muitas dificuldades: "Nós criamos um grupo de coordenação estadual que se reunia com a transferência das regiões, eu morava na fronteira oeste do Rio Grande do Sul e ia para Porto Alegre, pegava carona, não tinha duas passagens, era tudo muito difícil" (Rodrigo, 29 anos).

Construir um movimento social com e para os(as) jovens representa uma das grandes novidades inauguradas pelo LPJ. Durante a pesquisa, acompanhamos o Movimento em suas atividades e observamos uma profunda dedicação coletiva em fazer e construir o Movimento com o jeito juvenil de ser, aliando a ludicidade, a irreverência, a criatividade, mas também o compromisso político em manter uma organização social da juventude. Esse projeto com e para os(as) jovens se materializa em seu modelo organizativo que pode ser observado durante os eventos: acampamento nacional e estadual, seminários, encontros, Estágio de Vivência, entre outros em que os(as) jovens fazem efetivamente os espaços acontecerem, colocam "a mão na massa".

Reunir a juventude da cidade e do campo e unificar suas demandas em torno de um projeto comum para ela representa um grande desafio, uma vez que a juventude é una e diversa (DAMASCENO, 2004). Desse modo, para melhor compreender as formas como os(as) jovens estão fazendo política, partimos da linguagem, dos exercícios políticos e da própria forma de organização dos(as) jovens que constitui o LPJ. A diversidade encontrada dentro do LPJ parece estar sendo canalizada para a luta social como horizonte maior em defesa de uma sociedade mais livre e justa, tolerante aos modos de existência juvenil no tempo presente.

Os passos traçados no percurso da pesquisa revelam que os(as) jovens chegam até o LPJ por diversas razões/motivações. Uma delas é a necessidade de se sentirem parte de uma organização, de um coletivo, e por entenderem que dentro do grupo se expressa certa força na sociedade, ou seja, ele tem capacidade de criar alternativas e "espaços de construção de um devir, onde podem agir, falar, lutar, produzir” (SALES, 2018, p. 27).

Dessa maneira, os(as) jovens instalam um grito que anuncia que eles(as) sabem falar de si, negando a desqualificação de seus discursos e práticas. Os(as) jovens despertam o interesse em estarem organizados durante sua trajetória escolar, alguns com experiências do ensino médio, outros já na universidade, na qual buscam, no movimento estudantil, um atalho para depois vir a ser parte do LPJ.

A pesquisa mostrou que a instituição escolar também é lugar de resistência, indignação e esperança, na qual é possível pensar e problematizar o lugar social e político da juventude brasileira. Exemplo revelador disso foram todas as manifestações, ocupações e mobilizações que os(as) jovens secundaristas, universitários e de outros coletivos, inclusive do LPJ, realizaram entre os anos de 2013 a 2017 no Brasil.

Por outro lado, é importante destacarmos acerca dos limites das ações, uma vez que é fundamental uma formação que oriente para uma prática verdadeiramente questionadora, problematizadora e libertadora (FREIRE, 1987). Uma educação para além dos interesses e controle da classe burguesa se torna fundante na tentativa de uma prática "revolucionária", uma vez que a teoria e a ação se complementam e são um indicativo da práxis humana.

Desenvolver uma concepção de educação/formação que caminhe na direção de formar sujeitos críticos e reflexivos é o grande desafio da formação no LPJ, sobretudo no contexto atual da sociedade brasileira em que a educação e toda forma de saber/conhecimento estão sendo suplantadas pelo modelo de ignorância do atual governo. 


\section{Referências}

ALONSO, Ângela. As teorias dos movimentos sociais: um balanço do debate. Lua Nova: Revista de Cultura e Política, São Paulo, n. 76, p. 49-86, 2009.

ARENDT, Hannah. A condição humana. Tradução de Roberto Raposo. 11. ed. Rio de Janeiro: Forense Universitária, 2010.

ARENDT, Hannah. Entre o Passado e o Futuro. São Paulo: Perspectiva, 2003.

CADERNO DE DEBATES 1. Levante Popular de Juventude. Belo Horizonte: ABC, 2016.

CADERNO DE DEBATES 1. Levante Popular de Juventude. Belo Horizonte: ABC, 2018.

CARRANO, Paulo. Juventudes e Cidades Educadoras. Petrópolis: 2003.

DAGNINO, Evelina. Sociedade civil, participação e cidadania: de que estamos falando? Caracas: FACES, Universidade Central da Venezuela, 2004.

DAMASCENO, Maria Nobre. Formação da juventude e valores. Fortaleza: Expressão gráfica e editora, 2013.

DAMASCENO, Maria Nobre. Entre o sonho e a realidade: educação e perspectivas de trabalho para os jovens. Fortaleza: Editora Brasil Tropical, 2004.

DAYRELL, Juarez. O jovem como sujeito social. Revista Brasileira de Educação, Rio de Janeiro, n. 24, p. 40-52, set./dez. 2003.

FORACCHI, Marialice Mencarani. O estudante e a transformação da sociedade brasileira. São Paulo: Companhia das Letras, 1977.

FREIRE, Paulo. Pedagogia do oprimido. Rio de Janeiro: Paz e Terra, 1987.

MELUCCI, Alberto. Por uma sociologia reflexiva: pesquisa qualitativa e cultura. Tradução de Maria do Carmo Alves do Bomfim. Petrópolis: Vozes, 2001.

PAIS, José Machado. Culturas juvenis. Lisboa: Imprensa Nacional Casa da Moeda, 2003.

SAFATLE, Vladimir. Amar uma ideia. In: HARVEY, David et al. Occupy: movimentos de protesto que tomaram as ruas. São Paulo: Boitempo: Carta Maior, 2012. p. 45-55.

SALES, Celecina de Maria Veras. Ocupar e resistir. Life Research Group Blog, ICS-Lisboa. Lisboa, 4 set. 2018. Disponível em: https://liferesearchgroup.wordpress.com/2018/09/04. Acesso em: 15 set. 2018.

SCHERER-WARREN, Ilse. Dos movimentos sociais às manifestações de rua: o ativismo brasileiro no século XXI. Florianópolis: política e sociedade, 2014.

STECANELA, Nilda. Jovens e cotidiano: trânsitos pelas culturas juvenis e pela "escola da vida". 2008. Tese (Doutorado em Educação) - Faculdade de Educação, Universidade Federal do Rio Grande do Sul, Porto Alegre, 2008.

VIA CAMPESINA. In: CALDART, Roseli Salete; PEREIRA, Isabel Brasil; ALENTEJANO, Paulo; FRIGOTTO, Gaudêncio (org.). Dicionário da Educação do Campo. Rio de Janeiro: Escola Politécnica de Saúde Joaquim Venâncio; São Paulo: Expressão Popular, 2012. p. 765.

ZIBECHI, Raúl. Territórios em resistência: cartografia política das periferias urbanas latino-americano. Rio de Janeiro: Consequência, 2015.

Data de submissão: 30/01/2021

Data de aceite: 10/02/2021 
